\title{
Iodine Status of Breastfed Infants and their Mothers after Sixteen Years of Universal Dietary Salt Iodization Program in Dosso, Niger
}

\author{
Hassimi Sadou $^{2} *$, Yaou Moussa ${ }^{1}$, Mousbahou Malam Alma ${ }^{2}$ and Hamani Daouda ${ }^{1}$ \\ ${ }^{1}$ Laboratoire de Nutrition Humaine. Faculté des Sciences et Techniques. Université Abdou, Moumouni. BP: 10662 \\ Niamey. Niger \\ ${ }^{2}$ Biochimiste - Nutritionniste Maître de Conférences Université Abdou Moumouni Faculté des Sciences, BP: 10662 \\ Niamey. République du Niger
}

\begin{abstract}
Introduction: Universal dietary salt iodization (UDSI) was implemented in Niger in 1996. However, since 2000 there was a slowdown in progress against iodine deficiency.

Objective: The objective was to assess iodine nutritional status of infants and their lactating mothers living in Dosso, the state capital of a severe iodine deficiency region in Niger.

Methods: The study was centered on 238 full-term infants and their mothers. Some of the data collected were: arm circumference (AC), head circumference (HC) of infant; familial thyroid disease history; the infant feeding method; age of the mother and child; parity, occupation and educational level of the mother.

Results: In infants, the urinary iodine concentration (UIC) ranged from 20 to $1600 \mu \mathrm{g} / 1$ with a median of $220 \mu \mathrm{g} / \mathrm{L}$ and $17.23 \%$ had iodine deficiency (UIC $<100 \mu \mathrm{g} / \mathrm{L}$ ). In mothers, the UIC was within 10 and $820 \mu \mathrm{g} / \mathrm{L}$ with a median of 68 $\mu \mathrm{g} / \mathrm{L}$ and $69.75 \%$ had iodine deficiency. No significant statistical correlation was found between infant UIC and their age, type of feeding and gender as well as educational level, occupational group, parity and age of their mothers $(\mathrm{p}>0.05)$. Spearman's correlation test indicated weak significant correlation between maternal and infant UIC $(r=0,167, p=0,01)$.
\end{abstract}

Conclusion: Iodine status was suboptimal in $70 \%$ of mothers and $17 \%$ (mild to moderate) of breastfed infants, thus indicating an urgent need to provide iodine supplement for lactating women in Dosso.

Keywords: Urinary iodine concentration, infants, lactating women, Iodine nutrition, Niger.

\section{INTRODUCTION}

Iodine is an essential trace element for human health whose deficiency is responsible for various pathologies commonly called iodine deficiency disorders (IDD) [1-4]. The first national survey on IDD conducted in 1994, in schools showed that Niger was among the countries south of Sahara affected by iodine deficiency [5]. This survey was centered on 8933 schoolchildren aged 10-15yrs. The total goiter rate was $35.8 \%$, ranging from $21 \%$ in Niamey to $44 \%$ at Dosso and Tahoua. Visible goitre was $5.7 \%$ and the highest rates were found in Dosso (10\%), Tahoua (9\%) and Maradi (8\%) regions. Urinary iodine from 795 pupils gave a median urinary iodine concentration (UIC) of $34 \mu \mathrm{g} / \mathrm{L}$, ranging from 10 to $940 \mu \mathrm{g} / \mathrm{L}$. About $90 \%$ of the pupils tested had UIC below $100 \mu \mathrm{g} / \mathrm{L}$ [5]. In 1996, universal dietary salt iodization (UDSI) was adopted by Niger as a strategy for prevention, control, and elimination of iodine deficiency[6]. Thus, the

\footnotetext{
*Address correspondence to this author at the Laboratoire de Nutrition Humaine. Faculté des Sciences et Techniques. Université Abdou, Moumouni. BP : 10662 Niamey. Niger; Tel: 227969737 80;

227903801 81; Fax: 227203158 62; E-mail: hassimi@yahoo.com;

hassimi.sadou@gmail.com
}

production, importation, distribution and marketing of dietary iodized salt were made mandatory by an interministerial act in October 1995 which came into force on 1 April 1996 [6]. A system of quality control of dietary iodized salt was introduced, reinforced by devices at the customs offices, distribution channels and sales.

A 1998 survey two years after introduction of iodized salt assessed 944 pupils from 237 primary schools in eight regions of the country. The use of iodized salt led to an increase in iodine content of urine. Thus, the median UIC increased from $34 \mu \mathrm{g} / \mathrm{L}$ in 1994 to $270 \mu \mathrm{g} / \mathrm{L}$ in 1998 , with range of 116 to $796 \mu \mathrm{g} / \mathrm{L}$. The percentage of schoolchildren with normal urinary iodine excretion increased from 10 to $77.3 \%$. The total goiter rate decreased from $35.8 \%$ to $20.4 \%$ and the visible goiter from $5.7 \%$ to $1.4 \%$. The 1998 study obtained 894 dietary salt samples from retailers, and found $64 \%$ with iodine content $>25 \mathrm{ppm}$ against $7 \%$ before the UDSI program [5, 7]. However, from the year 2000 there was a lack of control of iodized dietary salt quality. According to the second Multiple Indicator Survey, 44\% of households were consuming dietary iodized salt in 2000 , which indicates a decrease of $20 \%$ over 1998 [8]. In 2001 the ThyroMobil visited selected sites; the median UIC was 54 
$\mu \mathrm{g} / \mathrm{L}$, in sharp contrast to the 1998 data [5]. In 2006, of the 1000 dietary salt samples collected from retailers in the eight regions of Niger, $78.7 \%$ had iodine content below $25 \mathrm{ppm}$ $[9,10]$. In 2010, 229 samples of imported dietary salt were collected at the customs office at the entrance of the Niamey urban community; $67.2 \%$ had iodine content below $30 \mathrm{ppm}$ and $52.4 \%$ had iodine content of less than $15 \mathrm{ppm}$ [11]. During the same survey, 250 samples were collected from retailers, $98.2 \%$ had iodine content below $30 \mathrm{ppm}$ and $87.6 \%$ had iodine content less than $15 \mathrm{ppm}$ [11]. The same year, $32.6 \%$ of infants consulted in the Niamey Urban Community primary health centres had UIC below $100 \mu \mathrm{g} / \mathrm{L}$ [12].

Above observations thus confirm a slowdown in progress against iodine deficiency in Niger since the good results of 1998. It is therefore urgent to assess the impact of reducing the coverage of iodized salt on people's health at least for vulnerable groups. Indeed, data from several countries indicated that lack of a well monitored dietary salt iodization (DSI) program is accompanied by recurrence of iodine deficiency [13]. The aim of our study was to assess iodine status of mothers and their infants in a context where national controls are not effective at ensuring universal availability of adequate dietary iodized salt. The study was conducted in Dosso town because this region is one of the most affected by IDD [5]; it is also bounded by two international borders that make it even more difficult to control the importation, distribution and marketing of iodized salt. This study was centred on neonates and infants aged 1-17 months and their lactating mothers because up till today no data were available on these groups whereas this period is still critical for brain damage resulting from iodine deficiency. Moreover, for infants under six months of age, breast milk is the major source of iodine for thyroid hormones biosynthesis, followed by infant fortified iodine formula [14-16].

\section{SUBJECTS AND METHODS}

This cross-sectional study took place in the three Integrated Health Centers (IHC) of the state capital of Dosso in Niger. The study was centered on 238 full-term infants and their lactating mothers seen in infant consultation in the three (IHC). Participation in the study was voluntary and exclusion criteria were: refusal of the mother to participate in the study, children who were not breast-fed, children who have not been brought by their mothers, children whose urine could not be collected, children exposed to disinfectants, antiseptics or contrast agents containing iodine. The protocol is in accordance with the Helsinki Declaration of 1975 as revised in 2008 and informed consent was obtained from each participant recruited.The study was endorsed by the National Ethics Committee and the
Academic Scientific Council of Abdou Moumouni University. Some of the data collected were: age, gender, arm circumference (AC), head circumference (HC), the infant feeding method, family history of thyroid disease, parity, maternal occupational group and level of education (not enrolled, primary, secondary + higher).

The ratio $\mathrm{AC} / \mathrm{HC}$ assessed the nutritional status of children between one month and 5 years [17]. The measurement of urinary iodine concentrations (UIC) was used as a criterion for the assessment of nutritional status in iodine. Casual urine samples were used for assessment of UIC [1]. The urine samples were analysed using the method of Wawschinek as modified by Dunn et al [18]. The statistical analysis was carried out using SPSS 17.0 program (Chicago, Il, USA). Kholmogorov-Smirnov test was used to assess normality of UIC. Mann-Whitney U test was used for differences between two groups; Kruskal-Wallis were used for comparison of all groups. $\mathrm{P}<0.05$ was considered significant.

\section{RESULTS}

The 238 infants were aged 1-17 months (mean \pm SD: $5.97 \pm 3.36$ months) out of which $124(52.10 \%)$ were less than 6 months. One hundred and twenty five infants $(52.52 \%)$ were male and one hundred and thirteen infants were female $(47.48 \%)$. One hundred and twenty three infants $(51.68 \%)$ were exclusively breastfed and one hundred and fifteen infants $(48.32 \%)$ mixed-fed. The 238 mothers were aged 16 to 53 years (mean \pm SD $27.95 \pm 7.05$ years). Forty two $(17.65 \%)$ mothers were aged between 16 and 20, fifty six $(23.53 \%)$ between 21 and 25 , sixty-seven $(28.15 \%)$ between 26 and 30 and seventy-three $(30,67 \%)$ aged over 30 years. One hundred and forty two $(59.66 \%)$ mothers were not enrolled, fifty seven $(23.95 \%)$ had a primary level of education and thirty nine $(16.39 \%)$ a secondary or higher education. Two hundred and six $(86.55 \%)$ mothers were housewives and thirty two $(13.45 \%)$ had an income generating activity (teachers, retailers resellers, cashiers, tailors).

The Nutritional status of infants according to $\mathrm{AC} / \mathrm{HC}$ ratio expressed in Table $\mathbf{1}$ showed that malnutrition was a major public health problem in these infants. About $60 \%$ of them suffered from mild to moderate malnutrition and $1.2 \%$ was severely malnourished. No significant relationship was found between iodine status and $\mathrm{AC} / \mathrm{HC}$ ratio $(\mathrm{P}=0.08)$.

The median UIC of the infants was $220 \mu \mathrm{g} / \mathrm{L}$ which is higher than the median UIC criterion $(\geq 100 \mu \mathrm{g} / \mathrm{L})$ recommended by WHO/UNICEF/ ICCIDD [1]. The percentage of children with UIC below $50 \mu \mathrm{g} / \mathrm{L}$ was far lower than the $20 \%$ tolerated in a given population and no child suffered

Table 1. Nutritional Status of Infants According to AC/HC Ratio

\begin{tabular}{|l|l|l|}
\hline \multicolumn{1}{|c|}{ AC/HC Ratio } & \multicolumn{1}{|c|}{ Nutritional Status } & \multicolumn{1}{c|}{ Percent (n) of Infants } \\
\hline \hline$<0.25$ & Severe & $1.26 \%(3)$ \\
$0.25-0.28$ & Moderate & $15.55 \%(37)$ \\
$0.29-0.31$ & Mild & $44.12 \%(105)$ \\
$>0.31$ & Normal & $39,07 \%(93)$ \\
\hline
\end{tabular}


Table 2. Urinary Iodine Concentration (UIC) and Percent below Cut-off Points that Indicated Suboptimal Status of Iodine Nutrition for All Infants and their Lactating Mothers

\begin{tabular}{|l|l|l|}
\hline \multicolumn{1}{|c|}{ Parameters } & \multicolumn{1}{c|}{ All Infants } & \multicolumn{1}{c|}{ All Lactating Mothers } \\
\hline \hline $\mathrm{N}$ & 238 & 238 \\
$\mathrm{Mean}$ Age $($ Month $/$ year $)$ & $5.97 \pm 3.36$ & $27.95 \pm 7.05$ \\
Median UIC $(\mu \mathrm{g} / \mathrm{L})$ & 220 & 68 \\
$20^{\text {th }}$ Percentile UIC $(\mu \mathrm{g} / \mathrm{L})$ & 107.20 & 40 \\
& & $36.13 \%(86)$ \\
Percent with UIC UIC $<50 \mu \mathrm{g} / \mathrm{L}$ & $3.78(9)$ & $69.75 \%(166)$ \\
Percent with UIC UIC $<100 \mu \mathrm{g} / \mathrm{L}$ & $17.23(41)$ & $83.19 \%(198)$ \\
Percent with UIC UIC $<150 \mu \mathrm{g} / \mathrm{L}$ & $34.03(81)$ & \\
\hline
\end{tabular}

Figures in parentheses are the number of infants or lactating mothers

Table 3. Distribution (Percent) of Urinary Iodine Concentration (UIC) of All Infants and Lactating Mothers According to Range of UIC and Status of Iodine Nutrition

\begin{tabular}{|l|l|l|l|}
\hline \multicolumn{1}{|c|}{ Rang UIC $(\boldsymbol{\mu g} / \mathbf{L})$} & \multicolumn{1}{|c|}{ Status of Iodine Nutrition } & \multicolumn{1}{c|}{ All Infants } & \multicolumn{1}{c|}{ All Lactating Mothers } \\
\hline \hline$<20$ & Severe & 0 & $2.10 \%(5)$ \\
$20-49$ & Moderate & $3,78(9)$ & $34.03 \%(81)$ \\
$50-99$ & Mild & $13,45(32)$ & $33.61 \%(80)$ \\
$100-199$ & Normal & $27,73(66)$ & $18.91 \%(45)$ \\
$200-299$ & Risk of IIH* & $15,55(37)$ & $7.98 \%(19)$ \\
$>300$ & Risk of IIH* & $39,50(94)$ & $3.36 \%(8)$ \\
\hline
\end{tabular}

* IIH: Iodine-Induced Hyperthyroidism

Figures in parentheses are the number of infants or lactating mothers

from severe deficiency (Table 2 and 3). However mild to moderate Iodine deficiency still affected $17 \%$ of the children (Table 2).

Median UIC of the lactating mothers $(68 \mu \mathrm{g} / \mathrm{L})$ was below the $100 \mu \mathrm{g} / \mathrm{L}$ defined as optimal [1]. About $70 \%$ of the lactating mothers had mild to moderate iodine deficiency and two $2 \%$ had severe iodine deficiency (Table 2 and 3 ). In addition, the percent of lactating mothers with UIC less than $100 \mu \mathrm{g} / \mathrm{L}$ was four times higher compared to their infants.

The Kholmogorov-Smirnov test indicated that the UIC were not normally distributed. No relationship was found between infant nutritional iodine status and age $(p=0.135)$, type of feeding $(\mathrm{p}=0.624)$ and gender $(\mathrm{P}=0.232)$ of the infants as well as educational level $(p=0.274)$, occupational group $(p=0.684)$, parity $(p=0.663)$ and age $(p=0.163)$ of the mothers. On the other hand significant relationship was found between maternal iodine status and their school level $(\mathrm{p}=0,006)$ and the infant age $(\mathrm{p}=0,008)$. Spearman's correlation test indicated very weak $(\mathrm{r}=0,167, \mathrm{p}=0,01)$ significant correlation between the UIC in lactating mothers and their infants.

The lactating mothers and their infants were grouped according to the infant feeding method: exclusive breastfeeding and breastfeeding mixed with baby foods / locally prepared gruels. Four sub-groups were constituted: exclusively breastfed Infants (EBF-Infants), mixed-fed-Infants (MFInfants), exclusively breastfeeding mothers (EBF-Mothers) and mixed-feeding mothers (MF- Mothers). The mean age of
EBF-Infants was $3.63 \pm 1.46$ months and the median age was 3 months. The mean age of MF-Infants was $8.49 \pm 2.99$ months and the median age was 8 months. The EBF-Infants were significantly younger $(p=0,000)$ than the MF-Infants.

The UIC and iodine nutrition status for EBF-Infants and MF-Infants are presented in Tables $\mathbf{4}$ and 5. Percent of MFInfants with UIC below the cut-off points for optimal status of iodine nutrition was relatively lower compared to that of EBF-Infants, but no difference was observed in their median UIC.

Approximately two thirds of MF-Mothers and three quarters of EBF-Mothers were deficient in iodine. Severe iodine deficiency was observed in 4\% EBF-Mothers. The Spearman's correlation test indicated weak $(\mathrm{p}=0,032, \mathrm{r}=$ $0,194)$ significant linear relationship between the UIC of EBF-Infants and EBF-Mothers. A weak non-significant linear relationship $(r=0,145, p=0,125)$ was found between the UIC of the MF-Infants and MF-Mothers.

\section{DISCUSSION}

According to WHO, for lactating women and children $<2$ years of age a median UIC of $100 \mu \mathrm{g} / \mathrm{l}$ can be used to define adequate iodine intake, but no other categories of iodine intake are defined $[1,19]$. In the present study, the median UIC of the breastfed infants was higher than the recommended adequate minimum UIC of $100 \mu \mathrm{g} / \mathrm{L}$. In addition, less than $5 \%$ of the infants had UIC below $50 \mu \mathrm{g} / \mathrm{L}$ 
Table 4. Urinary Iodine Concentration (UIC) and Percent below Cut-off Points that Indicated Suboptimal Status of Iodine Nutrition Status for Exclusively Breastfed Infants (EBF-Infants), Mixed-fed-Infants (MF-Infants), Exclusively Breastfeeding Mothers-(EBF-Mothers) and Mixed-feeding Mothers (MF- Mothers)

\begin{tabular}{|l|l|l|l|l|}
\hline \multicolumn{1}{|c|}{ Parameters } & \multicolumn{1}{|c|}{ EBF-Infants } & \multicolumn{1}{|c|}{ MF-Infants } & \multicolumn{1}{|c|}{ EBF-Mothers } & \multicolumn{1}{c|}{ MF-Mothers } \\
\hline \hline $\mathrm{N}$ & 123 & 115 & 123 & 115 \\
Mean age (Month/year) & $3.63 \pm 1.46$ & $8.49 \pm 2.98$ & $27.22 \pm 6.25$ & $28.72 \pm 7.69$ \\
Median UIC $(\mu \mathrm{g} / \mathrm{L})$ & 220 & 220 & 60 & 68 \\
$20^{\text {th }}$ Percentile UIC $(\mu \mathrm{g} / \mathrm{L})$ & 100 & 120 & 40 & 40 \\
& & & & \\
Percent with UIC: $<50 \mu \mathrm{g} / \mathrm{L}$ & $2.44(3)$ & $5.22(6)$ & $36.58(45)$ & $36.65 \%(41)$ \\
Percent with UIC: $<100 \mu \mathrm{g} / \mathrm{L}$ & $18.70(23)$ & $15.65(18)$ & $76.42(94)$ & $63.61 \%(72)$ \\
Percent with UIC: $<150 \mu \mathrm{g} / \mathrm{L}$ & $39.58(45)$ & $31.30(36)$ & $87.80(108)$ & $78.26 \%(90)$ \\
\hline
\end{tabular}

Figures in parentheses are the number of infants or lactating mothers

Table 5. Distribution (Percent) of Urinary Iodine Concentration (UIC) of Exclusively Breastfed-infants (EBF-Infants), Mixed-Fedinfants (MF-Infants), Exclusively Breastfeeding-mothers (EBF-Mothers), Mixed-feeding-Mothers (MF-Mothers) According to Range of UIC and Status of Iodine Nutrition

\begin{tabular}{|c|c|c|c|c|c|}
\hline Rang UIC ( $\mu \mathrm{g} / \mathrm{L})$ & $\begin{array}{l}\text { Status of Iodine Nutri- } \\
\text { tion }\end{array}$ & $\begin{array}{c}\text { EBF-Infants }(N= \\
123)\end{array}$ & MF-Infants (N = 115) & $\begin{array}{l}\text { EBF-Mothers } \\
\qquad(\mathrm{N}=123)\end{array}$ & $\begin{array}{c}\text { MF-Mothers } \\
\text { (N = 115) }\end{array}$ \\
\hline$<20$ & Severe & 0 & 0 & $4,07(5)$ & 0 \\
\hline $20-49$ & Moderate & $2.44(3)$ & $5.22(6)$ & $32.52(40)$ & $35.65 \%(41)$ \\
\hline $50-99$ & Mild & $16.26(20)$ & $10.43(12)$ & $39.84(49)$ & $26.96 \%(31)$ \\
\hline $100-199$ & Normal & $28.46(35)$ & $26.96(31)$ & $14.63(18)$ & $23.48 \%(27)$ \\
\hline $200-299$ & Risk of IIH* & $13.00(16)$ & $18.26(21)$ & $5.69(7)$ & $10.43 \%(12)$ \\
\hline$>300$ & Risk of IIH* & $39.84(49)$ & $39.13(45)$ & $3.25(4)$ & $3.48 \%(4)$ \\
\hline
\end{tabular}

* IIH: Iodine-Induced Hyperthyroidism

Figures in parentheses are the number of infants or lactating mothers

and severe iodine deficiency (UIC $<20 \mathrm{mcg} / \mathrm{L}$ ) was not observed in any age group. This, according to the WHO/UNICEF/ICCIDD criteria indicated an optimal status of iodine nutrition [1].

The median UIC $(220 \mu \mathrm{g} / \mathrm{L})$ observed in this study for all breastfed infants was higher than values reported for infants in iodine sufficient population in other countries, for example, in France, in Italy and in New Zealand [15,17,20, 21]. In addition, the prevalence of mild to moderate iodine deficiency was, in general, lower than the values reported in the countries mentioned above. Niger adopted the Universal Dietary Salt Iodization (USI) program in 1996. However, our results seem suboptimal when we compared them with observations reported in some areas where the USI strategy was also implemented for example in China Iran and in Papua New Guinea [22-26]. In the present study, mild to moderate iodine deficiency still persisted at $17,23 \%$ of infants aged 1 to 17 months. When we considered the new cut-off point [13], 34\% of all the infants had UIC below 150 $\mu \mathrm{g} / \mathrm{L}$ which indicated suboptimal status of iodine nutrition. This should be a concern, because up to the age of two years, the brain of the infant is vulnerable to suboptimal intake of iodine, which may cause sub clinical iodine deficiency and thus have a devastating effect on child intelligence $[1,14]$.
The median UIC $(68 \mu \mathrm{g} / \mathrm{L})$ for breastfeeding mothers observed here was far lower than the recommended minimum adequate UIC of $100 \mu \mathrm{g} / \mathrm{L}$ and the prevalence of moderate to severe status of iodine nutrition $(36.14 \%)$ was higher than the $20 \%$ tolerated in a given population, indicating inadequate intake of dietary iodine [1]. When we considered the new cut-off point, $83 \%$ of all lactating mothers had UIC below $150 \mu \mathrm{g} / \mathrm{L}$; indicated that iodine deficiency was of public health significance in this population. Thus, despite the universal dietary salt iodization, breastfeeding women in our sample appeared more vulnerable on iodine nutrition status. The higher prevalence of suboptimal status of iodine nutrition among lactating mothers should be a concern, because of the association between sub clinical iodine deficiency in lactating mothers and the potential risk of abnormal brain development in breast-fed infants [27-30].

The median UIC observed in the present study for EBFInfants and MF-Infants was $220 \mu \mathrm{g} / \mathrm{L}$. This finding was different from that reported by Temple et al [23] whose reported median UIC for breast-fed infants was lower than that of mixed-fed and from that of Zhang et al [31] who, contrary, reported that the UIC of breast-fed infants was higher than that of mixed-fed although the difference was not statistically significant. Less than $20 \%$ of EBF-Infants and 
MF-Infants had UIC below $100 \mu \mathrm{g} / \mathrm{L}$. However using the new cut-off point, the UIC in $40 \%$ of EBF-Infants was below $150 \mu \mathrm{g} / \mathrm{L}$ compared to $31 \%$ in MF-Infants. Iodine deficiency must be considered as a major public health problem in these infants. The lower UIC in lactating women may partly be due to the loss of iodine in breast milk $[1,14]$. In addition, Dosso is a region bounded by two international borders making it difficult to control the importation, distribution and marketing of iodized salt. As we know customary taboo in the region prevents salt intake during pregnancy most especially when pregnant women's feet begin to swell but we do not have such information on lactating mothers.

Iodine deficiency had multiple adverse effects on growth and development in humans. Thyroid hormones are important for growth and development especially for the brain during the fetal period and the first year of life. Hence, it is important to ensure that the diet of lactating mothers contains adequate amounts of iodine knowing that maternal milk is the sole source of iodine for EBF-infants thyroid hormones formation whereas in MF-infants food intake could be a supplementary source of iodine [14].

The median UIC for EBF-Mothers was relatively lower than the median UIC of MF-Mothers. In addition $64 \%$ of MF-Mothers and $76 \%$ of EBF-Mothers had UIC below the cut-off points for optimal iodine status of $100 \mu \mathrm{g} / \mathrm{L}$ and severe iodine deficiency was observed in $4 \%$ of EBFMothers. However using the new cut-off point [13] 88\% of EBF-Mothers and 78\% of MF-Mothers had UIC below 150 $\mu \mathrm{g} / \mathrm{L}$. This indicated suboptimal status of iodine nutrition in both groups, with greater severity amongst the EBFMothers. The exacerbation of iodine deficiency observed among EBF-Mothers compared to MF- Mothers might be related to iodine excretion in milk [22]. Our results strongly indicated that iodine deficiency was a significant public health_problem in lactating mothers. An adequate dietary intake of iodine was needed during lactation not only to provide for breast-fed infants but also for maintaining the metabolic status of the mothers $[1,14,16,32]$.

Tables 3 and 5 showed the percent of infants and lactating mothers at risk of iodine-induced hyperthyroidism (IIH). Most individuals can tolerate relatively high intake of iodine without any obvious adverse effect $[1,14,33]$. However, excessive daily iodine intake (over $1000.0 \mu \mathrm{g}$ per day) may be potentially harmful to susceptible individuals $[1,14,23,33$ 35].

The Kholmogorov-Smirnov test indicated that the UIC were not normally distributed, thus non parametric tests were used to analyse the data. No significant relationship ( $p>$ 0.05 ) was found between infant nutritional iodine status and age, type of feeding, and gender of the infants as well as educational level, occupational group, parity and age of the mother. This confirmed previous observations reported from France [16]. However significant relationship was found between maternal iodine status and their educational level and the infant age $(p<0.05)$. Spearman's correlation test indicated weak $(\mathrm{r}=0.167, \mathrm{p}=0.01)$ significant correlation between the UIC in lactating mothers and their infants. Also weak significant correlation $(\mathrm{r}=0.194, \mathrm{p}=0.032)$ was observed between the UIC of EBF-Infants and EBFMothers. The correlation was weak and non-significant $(r=$
$0.145, p=0.125)$ between the UIC of the MF-Infants and MF-Mothers. Ours results are different from those of others that reported a weak and non significant correlation and a weak non significant negative correlation between the UIC of the EBF-Infants and EBF-Mothers and the UIC of the MF-Infants and MF-Mothers respectively [23].

\section{CONCLUSION}

The median UIC for the infants was above the $100 \mu \mathrm{g} / 1$ recommended cut-off point and 82.77 per cent had adequate iodine status of but mild to moderate iodine deficiency still existed in $17.23 \%$ of them. The prevalence of iodine deficiency was exacerbated (34.03\%) when the new cut-off point of $150 \mu \mathrm{g} / \mathrm{L}$ was considered. Iodine deficiency was a significant public health problem among lactating mothers as their median UIC value was below the range of optimal iodine status. In addition, only 30 percent of them had adequate iodine status and less than $17 \%$ when the new cutoff point of $150 \mu \mathrm{g} / \mathrm{L}$ was considered. Iodine deficiency was more severe in EBF-mothers compare to MF-mothers. Our results strongly suggested an urgent need to provide iodine supplement to lactating women in Dosso, Niger.

\section{DECLARATION OF INTEREST}

The authors declare that there is no conflict of interest that would prejudice the impartiality of this scientific work.

\section{FUNDING}

All authors declare this research did not receive any specific grant from any funding agency in the public, commercial or not-for-profit sector.

\section{CONFLICT OF INTEREST}

The authors confirm that this article content has no conflicts of interest.

\section{ACKNOWLEDGEMENT}

We thank all the lactating women who voluntarily participate to this study. We also thank all the nurses and the staff of the Primary Health Centres where this study took place.

\section{REFERENCES}

[1] World Health Organization / International Council for the Control of Iodine Deficiency Disorders/United Nations Children's Fund, Assessment of Iodine Deficiency Disorders and monitoring their elimination: A guide for program managers. $3^{\text {rd }}$ eds. Geneva: WHO. 2007.

[2] Hetzel BS. Iodine deficiency and fetal brain damage. N Engl J Med 1994; 332: 170-1

[3] Dunn JT. Iodine. In: Shils ME, Shike M, Ross CA, Caballero B, Cousins RJ, Eds. Modern Nutrition in Health and Disease. $10^{\text {th }}$ ed. Philadelphia: Lippincott Williams \& Wilkins. 2006; pp. 300-11.

[4] Zimmermann MB, Jooste PL, Pandav CS. Iodine-deficiency disorders. Lancet 2008; 372: 1251-62

[5] International Council for Control of Iodine Deficiency Disorders. Iodine deficiency disorders in Some Sub-Saharian Countries. IDD Newslett 2002; 18: 3-4.

[6] République du Niger. Arrêté interministériel no 61/MDI/CAT/ MSP/MPF du 4 octobre 1995 réglementant la production, l'importation et la commercialisation du sel iodé au Niger. 1995 
[7] Attama S, Seroussi M, Kourguéni AI, Koché H et Barrère B. Enquête Démographique et de Santé, Niger, 1998. Calverton, Maryland, U.S.A.: Care International [Niger] and Macro International Inc. 1999.

[8] Enquête à indicateurs multiples de la fin de la décennie. République du Niger : UNICEF. 2000.

[9] Daouda H. Enquête nationale sur les troubles dus aux carences en iode (TDCI) au Niger, Faculté des Sciences de la Santé, Université Abdou Moumouni. 2007

[10] Nurhlar SE, Lywane LI. Situational analysis of infant and young child nutrition policies and programmatic activities In Niger: Sara E. Wuehler* and Abdoulazize Biga Hassoumi. Matern Child Nutr 2011; 7: 133-56

[11] Mamane NH. Evaluation de la teneur en iode du sel alimentaire dans la Communauté Urbaine de Niamey. Thèse de doctorat. Niamey: Université Abdou Moumouni. Faculté des Sciences de la Santé. 2010; p. 74

[12] Seydou Y. Evaluation du taux d'iode urinaire chez les nourrissons sains vus en consultation PMI au CSI Boukoki de la communauté urbaine de Niamey. Thèse de doctorat. Niamey: Université Abdou Moumouni. Faculté des Sciences de la Santé. 2010; pp. 85

[13] Nazeri P, Mirmiran P, Mehrabi Y, Hedayati M, Delshad H, Azizi F. Evaluation of Iodine Nutritional Status in Tehran, Iran: Iodine Deficiency Within Iodine Sufficiency. Thyroid 2010; 20(12): 1399406.

[14] Delange F. Optimal iodine nutrition during pregnancy, lactation and the neonatal period. Int J Endocrinol Metab 2004; 2: 1-12

[15] Skeaff S.A, Ferguson EL, Mc Kenzie JE, Valeix P, Gibson RS, Thomson CD. Are breast-fed infants and toddlers in New Zeland at risk of iodine deficiency? Nutrition 2005; 21: 325-31.

[16] World Health Organization/ United Nations Children's Fund Joint statement by WHO and UNICEF : Reaching optimal iodine nutrition in pregnant and lactating women and young children. Geneva: WHO Publications, 2007: pp. 1-2

[17] Pouessel G, Bouarfa K, Soudan B, Sauvage J, Gottrand F, Turck D. Statut en iode et facteurs de risque de déficit en iode chez des enfants vus en consultation de protection maternelle et infantile dans la département du Nord. Arch Pediatr 2003;10: 96 - 101.

[18] Dunn JT, Crutchfield HE, Gutekunst R, Dunn AD. Methods for Measuring Iodine in Urine (ICCIDD/UNICEF/WHO). Netherlands: World Health Oranization1993; pp. 18-27

[19] International Council for Control of Iodine Deficiency Disorders. Iodine requirements in pregnancy and infancy. IDD NewsLett 2007; 23 (1): 1-2

[20] Valeix P, Preziosi P, Rossignol P, Farnier MA, Hercberg S. Iodine intakes assessed by urinary iodine concentrations in healthy children aged 10 months, 2 years and 4 years. Biol Trace Elem Res 1992; 32: 259-66.

[21] Rapa A, Marinello D, Chiorboli E, Sacco F, Bona G. Iodine deficiency in Italy. Lancet 1999; 354: 596-7.
[22] Wang Y, Zhang Z, Ge P, Wang Y, Wang S. Iodine status and thyroid function of pregnant, lactating women and infants $(0-1 \mathrm{yr})$ residing in areas with an effective Universal Salt Iodization program. Asia Pac J Clin Nutr 2009; 18: 34-40

[23] Temple VJ, Oge R, Daphne I, et al. Salt iodization and iodine status among infants and lactating mothers in Papua New Guinea. Afr J Food Agric Nutr Dev 2009; 9: 1807-23.

[24] Wang Y, Zhang Z, Ge P, Wang Y, Wang S. Iodine deficiency disorders after a decade of Universal Salt Iodization in a severe deficiency region in china. Indian J Med Res 2009; 130: 413-7

[25] Temple VJ, Haindapa B, Turare R, Masta A, Amoa AB, Ripa P. Status of iodine nutrition in pregnant and lactating women in national capital district, Papua New Guinea. Asia Pac J Clin Nutr 2006; 15: 533-7.

[26] Azizi F. Iodine nutrition in pregnancy and lactation in Iran. Public Health Nutr. 2007; 10: 1596-9.

[27] Bleichrodt N, Born MA. A meta analysis of research on iodine and its relationship to cognitive development. In: Stanbury J, Ed. The Damaged Brain of Iodine Deficiency: cognitive, behavorial, neuromotor, and educative aspects. New York: Cognizant Communication Corporation 1994; pp. 195-200

[28] Bleichrodt N, Escobar del Rey F, Morreale de Escobar G, Garcia I, RubioV. Iodine deficiency. Implication for mental and psychomotor development in children. In: Condiffe PG Delong GR, Robbins J, Eds. Iodine and the brain. New York: Plenum Press 1989; pp. 269-87

[29] Qian M., Wang D., Watkins W.E. The effects of iodine on intelligence in children: a meta-analysis of studies conducted in China. Asia Pac J Clin Nutr 2005; 14: 32-42

[30] Morreale de Escobar G, Obregon MJ, Escobar del Rey FE. Role of thyroid hormone during early brain development. Eur J Endocrinol 2004; 151: 25-32.

[31] Zhang JH, Xu H, Zhan L, Li X, Han YT. Effects of different feeding methods on the iodine status of the infants during the weaning period. Zhonghua Er Ke Za Zhi. 2003; 41 (7): 483-5.

[32] Yan YQ, Chen ZP, Yang XM, et al. Attention to the hiding iodine deficiency in pregnant and lactating women after universal salt iodization: A multi-community study in China. J. Endocrinol. Invest. 2005; 28(6): 547-53

[33] Delange F, Dunn JT. Iodine deficiency. In: Braverman LE, Utiger RD Eds. The thyroid: A Fundamental of Clinical Test. $9^{\text {th }}$ ed. Philadelphia: Lippincott Williams \& Wilkins 2005; pp. 264-88.

[34] Yang F, Shan Z, Teng X, et al. Chronic iodine excess does not increase the incidence of hyperthyroidism: a prospective community-based epidemiological survey in China. Eur J Endocrinol 2007; 156: 403-8.

[35] Teng W, Shan Z, Teng X, et al. Effect of iodine intake on thyroid diseases in China. N Engl J Med 2006; 354: 2783-93.

This is an open access article licensed under the terms of the Creative Commons Attribution Non-Commercial License (http://creativecommons.org/licenses/by-nc/3.0/) which permits unrestricted, non-commercial use, distribution and reproduction in any medium, provided the work is properly cited. 